\title{
THE ANALYSIS AND ADULTERATION OF FOODS,
}

By James Bexu, Pr. D., \&c., Principal of the Somerset House Laboratory.

Part II.-Published for the Committee of Council on Education by Chapman \& Hall. INSTEAD of reviewing this book at present, we reprint from it for the information of Public Analysts, the description of some of the processes used in the Somerset House Laboratory in the analysis of milk, and especially the description of the process which is carried out there for the analysis of sour milk.

Total Solids. - The determination of the total solid matter in fresh milk is a comparatively easy operation. Five grams of the milk are weighed in an accurately tared platinum capsule, which is placed on an aperture of a water-bath and at the end of about three hours, or less, when the residue is sufficiently dry, the capsule is removed to a water-oven to complete the drying. The capsule is afterwards weighed at intervals till a constant weight is obtained. It is important that the bottom of the capsule should be flat, or nearly so, and that the size should be such that, after the whole of the water has evaporated, the dry residue will be left in the form of a thin film.

It has sometimes been recommended, in order to facilitate perfect dryiug, that a known quantity of sand or pulverized glass should be added to the milk in the capsule; but this, according to our experience, is unnecessary, if care is taken to employ a capsule of the description mentioned.

Non-fatty Solids and Fat.-When the milk is fresh, a quantity of exactly 10 grams may be weighed in a platinum capsule containing a glass stirrer. The most suitable size of the capsule for this purpose is one having a diameter of 3 inches and a depth of 1 inch. The capsule is placed on an aperture of a water-bath, and its contents evaporated almost to dryness. It is of advantage to keep the milk well stirred during the process of drying, in order to insure that the solid residue be obtained in a condition favourable for the complete extraction of the fat. The milk residue should neither be too moist nor too dry, as either condition tends to prevent the removal of the last traces of fat. If the evaporation has been carried too far, the residue may be carefully moistened either with a very small quantity of water, or of alcohol. When the proper point has been reached, the mass is treated repeatedly with ether, the stirrer being each time used to pulverize the solid matter which, in order to insure that no portion escapes the action of the solvent, should assume a fine state of division. The ether is used warm for the last three treatments. After each washing the ethereal solution of the fat is carefully poured off through a small Swedish filter not exceeding $3 \frac{1}{2}$ inches in diameter. To remove the last traces of fat from the filter, the upper part is cut off, divided into small pieces, which are placed in the remaining portion of the filter in the funnel, and washed with a little ether. The filtrates are received into a tared beaker from which the ether is gently evaporated, and the fatty residue finally dried in a water-oven until the weight is constant.

The capsule containing the non-fatty residue is placed on the open water-bath for two hours, and subsequently for two or more hours in a closed water-oven kept at $212^{\circ} \mathrm{F}$. $\left(100^{\circ} \mathrm{C}\right.$.), until a constant weight is arrived at. This result should be obtained in the time stated if the milk solids have been finely pulverised in the process of fat extraction.

The determination of the fat, non-fatty solids and ash, should be made in duplicate; and, as a further check on the analysis, the total amount of milk solids may be ascertained 
in a third portion of the milk, which may afterwards be used for one of the determinations of the ash. It ought to be observed that, for some reason, probably connected in some way with the presence of fat, the final weighing of the total solids is seldom, if ever, so satisfactory as that of the non-fatty solids. In no case, therefore, would we advise that the nonfatty solids should be determined by deducting the weight of fat actually obtained from that of the total solids.

\section{ANALYSIS OF SOUR MILK.}

It not unfrequently happens that an analysis has to be made of samples of milk which have been kept for some time-that is, for a period of from two or three days to about four weeks-during which time the milk has become sour and coagulated. In such cases a slight diminution in the non-fatty solids will have taken place, as the result of an incipient form of fermentation which changes a portion of the milk-sugar chiefly into lactic acid, and, to a smaller extent, into alcohol and carbonic acid gas. It is, no doubt, owing to the formation of a little alcohol that the depreciation of the non-fatty solids is due, as milksugar changes into lactic acid practioally without any loss of weight; and as the acid is not volatile, its weight is correctly indicated on drying the milk. But the weight of the sugar decomposed by alcoholic fermentation is almost entirely lost, as the alcohol disappears on evaporation, and only the small portion of carbonic acid gas which is held in solution in the milk is retained on neutralizing the milk as after-mentioned. It is evident, therefore, that some allowance should be made for decomposition in the way of addition to the amount of non-fatty solids, according to the time the milk has been kept, in order to obtain a correct estimate of the composition of the milk before any change had taken place.

It has been alleged that the fat in sour milk increases at the expense of the albuminous matter; but the results of cur investigation show that the statement is without foundation. It is not unusual to obtain from sour milk about 05 per cent. of fat more than from the same milk in the fresh state, but this arises partly from the fact that, owing to the diminution of the non-fatty solids, 100 parts of the decomposed milk represent rather more than 100 parts of the mill in its original state, and partly from the greater ease with which the residue from neutralized sour milk can be brought into a fine state of division, thus enabling the ether to act more effectively in dissolving out the last trace of fat.

In estimating the non-fatty solids and fat in sour milks, it becomes necessary to adopt a modification of the process given for the analysis of fresh mill, as the lactic acid is soluble in ether, and would be found along with, and increase the weight of, the fat; and for the further reason that it is almost impossible to satisfactorily dry the milk in the presence of the free acid, without producing a serious loss in weight from decomposition. The following method has been found to give very accurate results :

Three suitable platinum capsules, two of which are supplied with glass-rods flattened at the ends, are weighed, and from 10 to 12 grams of sour milk, which has been thoroughly mixed by being whisked for a few minutes with a loose coil of fine brass wire, are introduced into each capsule, and the weight immediately ascertained. The separate quantities are exactly neutralised with pure decinormal soda solution, and the number of cubic centimetres required noted against each quantity. The contents of the two capsules containing the glass-rods are evaporated nearly to dryness, or until the residue attains the condition of a firm paste, a result which is promoted by occasionally stirring the contents towards the end of the evaporation. 
The third portion is brought to complete dryness, and the amount of total solids and ash estimated.

The fat is extracted with ether in the usual way, and the non-fatty solids brought to complete dryness on the water-bath. On evaporation of the ether from the extracted fat no traces of any of the milk solids will be found in the fat, if the neutralization of the mills has been properly effected. When the weights of the non-fatty solids have been ascertained, a deduction must be made for the added soda solution. The increase of weight arising from the soda is shown in the following equation:

$$
\begin{aligned}
& \mathrm{C}_{3} \mathrm{H}_{6} \mathrm{O}_{3}+\mathrm{NaHO}=\mathrm{C}_{3} \mathrm{H}_{5} \mathrm{NaO}_{\mathrm{a}}+\mathrm{OH}_{2} \\
& \text { Lactic acid + Soda }=\text { Sodic lactate + Water. }
\end{aligned}
$$

Every unit, therefore, of acid is increased by one unit of sodium, less the weight of an atom of hydrogen, which it replaces in the acid. This, reckoned according to the atomic weights, is equal to 22 . When, therefore, decinormal soda is used to neutralize the acid milk, every cubic centimetre used will add $\cdot 0022$ gram to the milk solids, and this weight multiplied into the total cubic centimetres used will give the amount to be deducted. A similar deduction is also made in the case of the total solids. The deduction to be made from the ash is in accordance with the fact that the soda added is converted into carbonate of soda on ignition of the milk residue, and the factor for multiplying into the number of cubic centimetres of soda employed is therefore 0053 gramme. The following actual experiment will illustrate the method :

Milk taken for total solids $=9 \cdot 517$ grams.

$7 \cdot 0$ c.c. $\frac{N}{10}$ soda-solution required to neutralize $\therefore 7 \cdot 0 \times \cdot 0022=0154$ grams.

Weight of dry total solids $=1.1390$ grams.

$\begin{array}{lllll}\text { Deduct .. } & \ldots & . & .0154 & \\ \text { Milk solids } & \ldots & . & 1.1236 & \end{array}$

$\frac{1.1236}{9.517} \times 100=11.80$ per cent. total solids.

Milk taken for Solids not Fat.

First Ifxperiment.

$\begin{array}{llll}\text { Milk } \quad . & . & \ldots & =8.223 \text { gms. } \\ \text { Soda solution required } & . . & =6.000 \text { c.c. } \\ \text { Dry residue } \quad . . & \ldots & =.720 \text { gm. } \\ \text { Deduct } 6.0 \times .0022 & \ldots & =\frac{.0132,}{.7068,},\end{array}$

$\frac{.7068 \times 100}{8.223}=\left\{\begin{array}{l}8.59 \text { per cent. of } \\ \text { non-fatty solids. }\end{array}\right.$

Dry fat .. = $267 \mathrm{gm}$.

$\frac{.267 \times 100}{8.223}=3.24$ per cent. of fat.

Ash residue

Deduct $7.0 \times .0053 \quad \ldots \quad \ldots=\frac{.0371}{.0729}$,

$$
\frac{.0729 \times 100}{9.517}=.76 \text { per cent. of ash. }
$$

The chlorine in the ash is estimated with $\frac{N}{10}$ silver-nitrate.

Required 3.0 c.c. to precipitate the $\mathrm{Cl}$. $\frac{.00355 \times 3.0 \times 100}{9 \cdot 517}=11$ per cent, chlorine,
Second Experiment.

$$
\begin{aligned}
& \text { Milk } \quad \text {. } \quad \ldots \quad \ldots \quad=8.728 \mathrm{gms} \text {. } \\
& \text { residue } \quad \ldots \quad \ldots=.765 \mathrm{gm} \\
& \text { Deduct } 6.4 \times 0022 \quad \ldots=.01408 \text {, } \\
& .75092, \\
& \frac{.75092 \times 100}{8.728}=\left\{\begin{array}{l}
8.60 \text { per cent. of } \\
\text { non-fatty solids. }
\end{array}\right. \\
& \text { Dry fat } \ldots=285 \mathrm{gm} \text {. } \\
& \frac{.285 \times 100}{8.728}=3.26 \text { per cent. of fat. } \\
& 0.110 \text { grams. } \\
& .0729
\end{aligned}
$$

.


It is impracticable accurately to estimate the non-fatty solids by first taking the weight of the dry total solids and deducting the weight of fat obtained from it, as it is difficult to get a constant weight for the dry solids when the fat has not been removed. It is necessary, therefore, to rely on the actual weight of the non-fatty solids, as these readily attain a constant weight without any sensible decomposition.

The allowance to be made for the loss which takes place in the non-fatty solids of milk is based upon the actual loss which has been found to occur in numerous samples of milk which have been analysed in a fresh state, and again at intervals, after the lapse of a certain number of days.

The depreciation or loss is fairly nniform for the same period of the year, but the amount varies within certain limits with the ordinary atmospheric changes of temperature, a slightly increased rate of depreciation occurring on a rise of temperature. The loss of non-fatty solids is relatively greatest during the first week of keeping, the amount for that period being on the average $\cdot 24$ per cent. ; for the second week the loss arerages $\cdot 10$ per cent. additional ; and for each day thereafter 01 per cent. According to this rate of allowance, the addition to be made to the non-fatty solids would be as follows for the number of days stated :

\begin{tabular}{|c|c|c|c|}
\hline 7 days & .. & .. & \\
\hline $14 \quad$ & .. & .. & $\cdot 3$ \\
\hline 21, & . & .. & $\cdot 4$ \\
\hline 28, & - & .. & $\cdot 4$ \\
\hline 35, & & & $\cdot 5$ \\
\hline
\end{tabular}

As already mentioned, a slight variation from these figures will be found, according to the conditions under which the milk has been kept; but the difference, whether greater or less, is generally indicated by the acidity of the milk, reckoned as lactic acid. With a carefully conducted analysis in the manner above described, the error, if any, in making the allowance should not exceed 10 per cent. of the non-fatty solids, and, in the case of watered milk, the result should come within one per cent. of the quantity of water added, as previously estimated from the analysis of fresh milk.

In the experiments upon the results of which these allowances are founded, the milk was kept in bottles filled to the extent of about three parts, securely corked, and maintained at such temperatures as might be ordinarily expected to apply to official samples retained for reference under the Sale of Food and Drugs Act.

Some tables of analyses of samples from individual cows and from dairies are given, and the author says: It will be seen from Table V. that in the case of individual cows the non-fatty solids vary from 8.00 to $11 \cdot 27$, the fat from 1.92 to 6.87 , and the ash from .62 to .87 per cent., while in the case of dairy samples in Table VI., the non-fatty solids vary from 8.50 to 9.91 , the fat from 2.95 to $5 \cdot 14$, and the ash from $\cdot 63$ to $\cdot 78$ per cent. The percentage of chlorine in the samples taken as a whole varies from $\cdot 08$ to $\cdot 14$ per cent.

Although these variations are considerable, it cannot be affirmed that they cover every case of low non-fatty solids which is occasionally met with in the milk of an individual cow. 